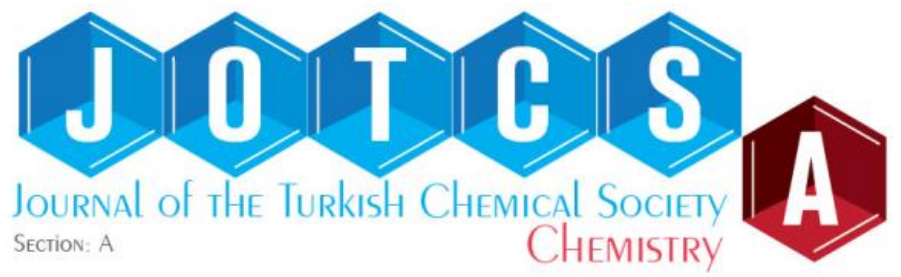

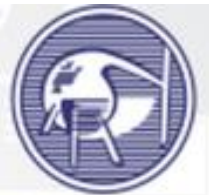

TURKISH

CHEMICAL SOCIETY

\title{
Study on the Preparation and Drug Release Property of Modified PEG-DA Based Hydrogels
}

\author{
Sebnem Senol $1 \square$ iD, Emel Akyol ${ }^{1} * \Delta$ iD \\ ${ }^{1}$ Department of Chemical Engineering, Yildiz Technical University, Istanbul, Turkey.
}

\begin{abstract}
The aim of the present study is to develop hydroxyapatite-modified PEGDA and PEG-DA/HEMA based hydrogels for release of Donepezil $\mathrm{HCl}$ for potential treatment of Alzheimer's disease. [2,2-Dimethoxy-2-phenyl-acetophenone] (Irgacure 651), 1 hydroxycyclohexyl phenyl ketone (Irgacure 184) and 2-hydroxy-4'-(2hydroxyethoxy)-2-methylpropiophenone (Irgacure 2959) were used as photoinitiators in the synthesis of hydrogels and hydroxyapatite was used for modifying hydrogels. Fourier transform infrared spectroscopy (FT-IR), scanning electron microscope (SEM) and digital microscope were utilized to investigate the characteristic properties of hydrogels. Photopolymerization technique was selected for the synthesis of hydrogels. Swelling and drug release studies have been performed under different $\mathrm{pH}$ conditions.
\end{abstract}

Keywords: Alzheimer's Disease, Hydrogels, Photopolymerization, Donepezil $\mathrm{HCl}$, Polyethylene diacrylate, 2-Hydroxyethyl methacrylate.

Submitted: November 20, 2018. Accepted: January 03, 2019.

Cite this: Senol S, Akyol E. Study on the Preparation and Drug Release Property of Modified PEG-DA Based Hydrogels. JOTCSA. 2019;6(1):1-14.

DOI: http://dx.doi.org/10.18596/jotcsa.485817.

*Corresponding author. E-mail: eakyol@yildiz.edu.tr.

\section{INTRODUCTION}

Many new classes of materials have been used to improve different innovative applications. Hydrogels, being cross-linked three-dimensional polymeric materials, have the ability to absorb large amounts of water. In recent years, hydrogels have an increasing demand for drug delivery systems. The purpose of the drug delivery systems is to maintain drug concentration in the blood or in target tissues at prolonging drug-release times (1-6).

Polyethylene glycol diacrylates (PEGDA) based polymers possess highly attractive properties that cause widely using in variety of applications 
such as tissue engineering, controlled drug delivery, and medicine areas. Polyethylene glycol diacrylate is nonvolatile, non-toxic, environmentally friendly, and also tailor-made into various shapes. Polyethylene glycol diacrylate acts as potential stabilizers and matrices for the formation of functional hydrogels (7-10).

Poly(2-hydroxyethyl methacrylate) (pHEMA), one of the synthetic watersoluble polymer, has been largely preferred, especially in various biomedical applications due to its chemical stability (11-12).

Hydroxyapatite (HAp), $\mathrm{Ca}_{10}\left(\mathrm{PO}_{4}\right)_{6}(\mathrm{OH})_{2}$, is a double salt of tricalcium phosphate and calcium hydroxide, and it is the main inorganic component of human bones and teeth. However, hydroxyapatite has an excellent biocompatibility and tissue bioactivity (13-16).

UV light polymerization is one of the main methods used in the synthesis of hydrogels in biomedical field. Considerable attention has been focused on photopolymerization method due to its broad applications. Nowadays, free radical polymerization with UV light is utilized in different applications such as coatings, information storage systems, films, contact lenses, and biomaterials. In the photopolymerization, the primary radicals were generated from light absorption of photoinitiator at a suitable wavelength thus polymerization and into highly crosslinked structures of multifunctional acrylates occurs (17-18).

Alzheimer's disease (AD) is the most common type of dementia that cause cognitive impairment and memory loss (19). The number of patients with $A D$ is projected to more than double by 2050. Although the etiology of AD has been elucidated, multiple questions remain unanswered (20-21).
Donepezil is a piperidine-based, reversible acetylcholinesterase (Ach) inhibitor generally used in the treatment of Alzheimer patients.

Donepezil prevents the hydrolysis of the residual Ach in the brain so it is the best pharmacological tool to decrease cognitive deficits in $A D$ patients. Donepezil has been investigated to be sufficient for enhancing of cognitive impairment and memory loss in patients with Alzheimer's disease. It is well efficient when $5 \mathrm{mg}$ of the drug is used once daily (22-27).

In this study, we aimed to develop prolonged drug release systems enhanced with HAp. We synthesized PEG-DA/HEMA based hydrogels with modified Hap via photopolymerization. Fourier transform infrared spectroscopy (FT-IR), scanning electron microscope (SEM) and digital microscope were utilized to investigate the characteristic properties of hydrogels. Modified PEG-Da/HEMA hydrogels were used for prolonging the release time.

\section{EXPERIMENTAL}

\section{Materials}

2-Hydroxylethyl methacrylate (HEMA), polyethylene glycol diacrylates $M_{n}=700$ (PEG-DA), ethylene glycol dimethacrylate, 2,2-dimethoxy-2phenyl-acetophenone (Irgacure 651, $99 \%$ purity), 1-hydroxycyclohexyl phenyl ketone (Irgacure 184, 99\% purity), 2-hydroxy-4'-(2hydroxyethoxy)-2-

methylpropiophenone (Irgacure 2959, $98 \%$ purity), hydroxyapatite (powder, $5 \mu \mathrm{m}$ and surface area $\geq 100 \mathrm{~m}^{2} / \mathrm{g}$ ), were supplied by Sigma-Aldrich. Donepezil $\mathrm{HCl}$ was a kind gift by Abdi İbrahim Company. Sodium chloride and hydrochloric acid were purchased from Merck. Sodium hydroxide and monobasic potassium phosphate were supplied from J.T Baker. All chemicals were used as received without further purification. 


\section{Preparation and characterization of PEG-DA/HEMA hydrogels}

PEG-DA/HEMA based hydrogels were prepared in the presence of a photoinitiator (Irg 184, Irg 651, Irg 2959) and a crosslinking agent (ethylene glycol dimethacrylate), as shown in Table 1 . The reactant mixtures were added to petri plates which consist of olive oil, using a micropipette. The reactant mixtures were deaerated by bubbling nitrogen gas during the reaction. Photopolymerization was performed at $365 \mathrm{~nm}$ under UV irradiation for a short time.
According to hydrogel type, $50 \%(\mathrm{w} / \mathrm{v})$ PEG-DA， 25\% (w/v) PEG-DA- 25\% $(w / v)$ HEMA and predetermined ratios of photo-initiators were mixed by using a magnetic stirrer at $50 \mathrm{rpm}$. Then, $0.07 \%(w / v)$ Donepezil $\mathrm{HCl}$ and deionized water were added. $0.5 \%$ ethylene glycol dimethacrylate was then introduced. After photopolymerization, hydrogels were washed with $\mathrm{n}$-hexane and dried at room temperature.

Table 1: Synthesis conditions for the PEG-DA/HEMA based hydrogels.

\begin{tabular}{|c|c|c|c|c|c|c|c|}
\hline Hydrogels & $\begin{array}{l}\text { PEG- } \\
\text { DA }\end{array}$ & HEMA & $\begin{array}{c}\text { EGDM } \\
\text { A }\end{array}$ & $\begin{array}{l}\text { Irg } \\
651\end{array}$ & $\begin{array}{l}\text { Irg } \\
184\end{array}$ & $\begin{array}{c}\text { Irg } \\
2959\end{array}$ & HAp \\
\hline $\begin{array}{c}\text { Hydrogel } 1 \\
\text { (H1) }\end{array}$ & $50 \%$ & - & $0.5 \%$ & $1 \%$ & - & - & $1 \%$ \\
\hline $\begin{array}{l}\text { Hydrogel } 2 \\
(\mathrm{H} 2)\end{array}$ & $50 \%$ & - & $0.5 \%$ & - & $1 \%$ & - & $1 \%$ \\
\hline $\begin{array}{c}\text { Hydrogel } 3 \\
\text { (H3) }\end{array}$ & $50 \%$ & - & $0.5 \%$ & - & - & $1 \%$ & $1 \%$ \\
\hline $\begin{array}{c}\text { Hydrogel } 4 \\
\text { (H4) }\end{array}$ & $25 \%$ & $25 \%$ & $0.5 \%$ & $1 \%$ & - & - & $1 \%$ \\
\hline $\begin{array}{c}\text { Hydrogel } 5 \\
\text { (H5) }\end{array}$ & $25 \%$ & $25 \%$ & $0.5 \%$ & - & $1 \%$ & - & $1 \%$ \\
\hline $\begin{array}{c}\text { Hydrogel } 6 \\
(\mathrm{H6})\end{array}$ & $25 \%$ & $25 \%$ & $0.5 \%$ & - & - & $1 \%$ & $1 \%$ \\
\hline
\end{tabular}

The equilibrium swelling ratios of the swollen hydrogels were measured using a gravimetric method in deionized water, $\mathrm{pH} 1.2,6.8$, and 7.4. Drug loaded hydrogels were used for swelling behavior at $37{ }^{\circ} \mathrm{C}$. At predetermined time points, the hydrogels were taken out and weighed after removal of surface water. Swelling and release analyses were repeated three times. A UV-Vis spectrophotometer (Analytikjena Specord 200/Plus) at $270 \mathrm{~nm}$ was used for release studies.

The determination of swelling ratio and preperation of buffer solution procedure has been reported previously in detail $(4,28)$.

\section{RESULTS AND DISCUSSIONS}

FT-IR Analyses of Hydrogels

For the imaging of photo-crosslinked PEGDA-based hydrogels, the attenuated total reflectance-FTIR (ATR-FTIR) scan was performed with a Perkin Elmer Spectrum 100 FTIR spectrometer. For each sample, a spectrum is obtained using the ATR utilizing a diamond internal reflection element mounted on a holder at a resolution of $4 \mathrm{~cm}^{-1}$ in the range 4000 $400 \mathrm{~cm}^{-1}$ for a total of 16 scans.

FT-IR spectra of the hydrogels are shown in Figure 1 . In the PEG-DA spectrum, there was an $-\mathrm{OH}$ at 3600 $\mathrm{cm}^{-1}$, a $\mathrm{CH}_{2}$ at $2853 \mathrm{~cm}^{-1}$, a $\mathrm{C}=\mathrm{O}$ at $1728 \mathrm{~cm}^{-1}$, and a $\mathrm{C}=\mathrm{C}$ at $1628 \mathrm{~cm}^{-1}$. For the PEG-DA/HEMA based hydrogels, there was an $-\mathrm{OH}$ bond at $3500 \mathrm{~cm}^{-1}, \mathrm{a} \mathrm{CH}_{2}$ at 2853 and 2956 $\mathrm{cm}^{-1}$, a $\mathrm{C}=\mathrm{O}$ at $1730 \mathrm{~cm}^{-1}$, a $\mathrm{C}=\mathrm{C}$ at 
$1610 \mathrm{~cm}^{-1}$, a $\mathrm{C}-\mathrm{OH}$ at $1059 \mathrm{~cm}^{-1}$. The bands at 1090 and $960 \mathrm{~cm}^{-1}$ are used for the characterization of phosphate stretching vibration and the bands observed at 598 and 559 and at 1020 $\mathrm{cm}^{-1}$ are due to the phosphate being in vibration. FT-IR analyses results confirm the combination of PEG-DA and HEMA.

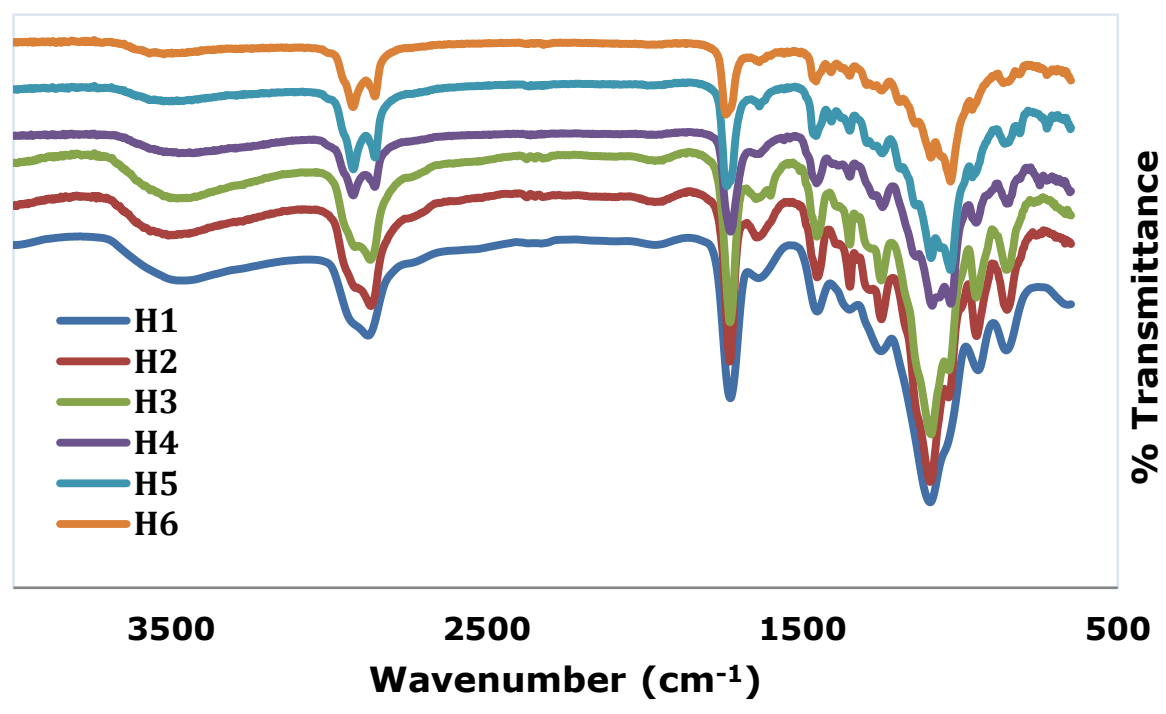

Figure 1. FT-IR spectra of the hydrogels.

\section{SEM Analysis of Hydrogels}

The sizes of hydrogels were obtained by digital microscope (Veho, VMS- 004 USB) Microscope (Figure 4). The textures of the hydrogels were examined by a conventional scanning electron microscopy (JEOL JSM 6335F). Figure 2 shows the SEM micrographs of PEG-DA based hydrogels using HAp as modified. The SEM morphology of $\mathrm{H} 1$ hydrogel showed a surface devoid of pores and cracks. Figure 3 shows the effect of incorporation of HEMA and PEG-DA on structure of hydrogels. While microparticles were formed in the presence of PEG-DA, the presence of HEMA revealed a spherical structure. The hydroxyapatite modified PEG-DA hydrogels were very different from and PEG-DA/HEMA based hydrogels. 

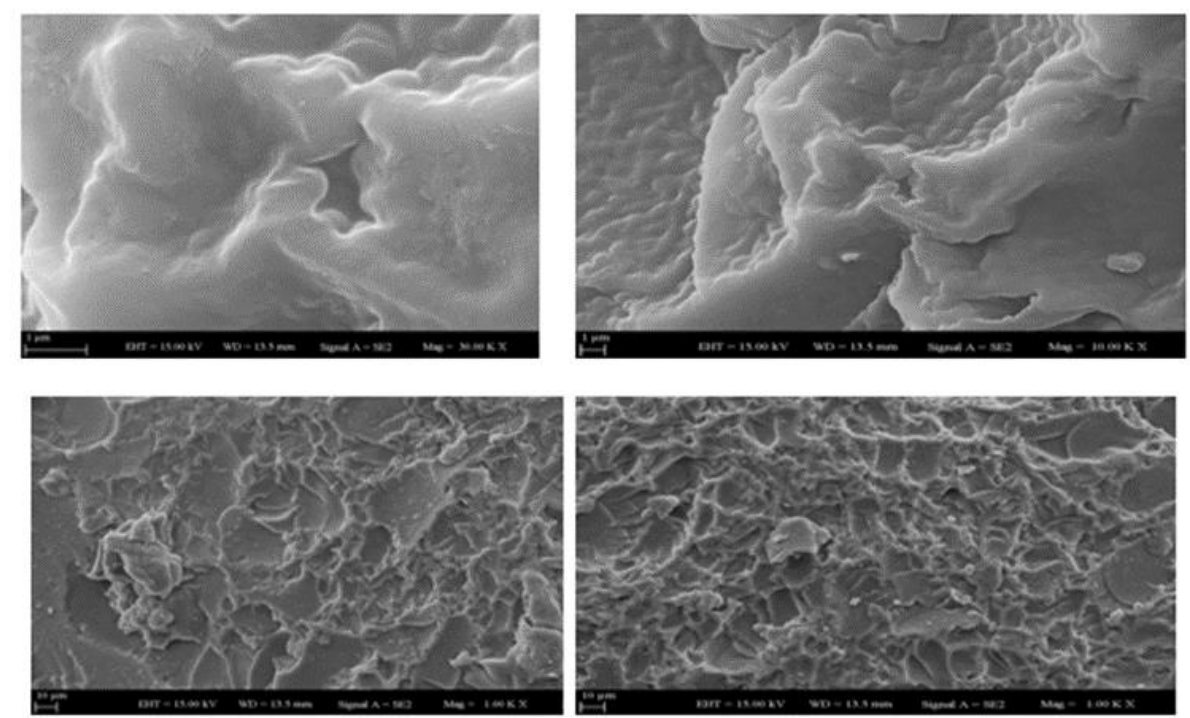

Figure 2: Scanning electron micrographs of H1 hydrogel.
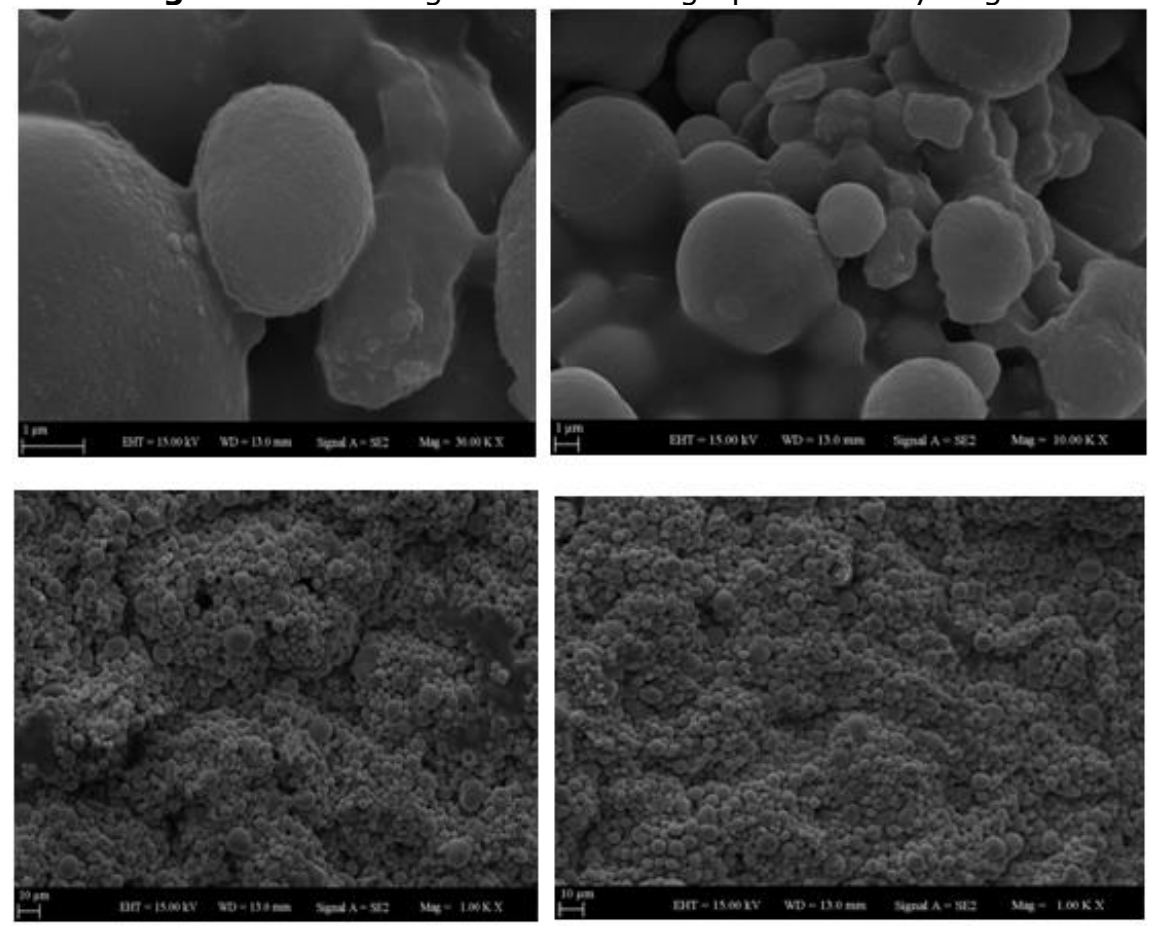

Figure 3: Scanning electron micrographs of $\mathrm{H} 6$ hydrogel. 

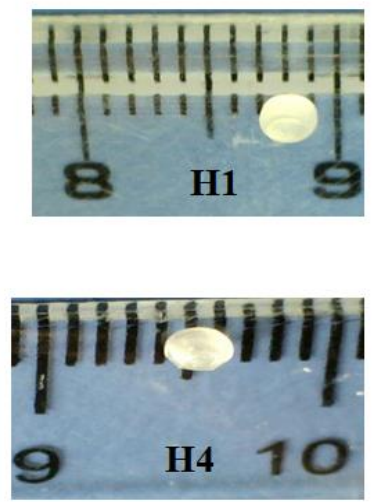
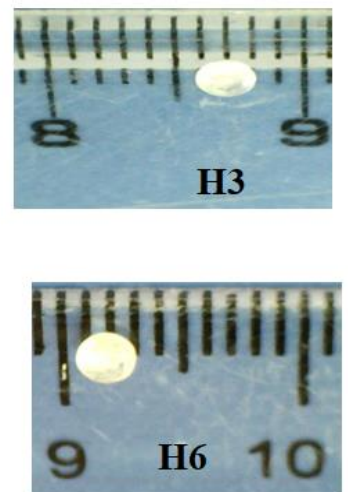

Figure 4: Digital microscope photos of synthesized hydrogels.

\section{Swelling tests}

In order to investigate the influence of the presence of $\mathrm{HAp}$ and $\mathrm{pH}$, swelling kinetics of PEG-DA and PEG-DA/HEMA based hydrogels were studied. Swelling ratios of the studied hydrogels after 240 minutes of immersion in water and solutions with of $\mathrm{pH} 1.2, \mathrm{pH} 6.8$ and $\mathrm{pH} 7.4$ at $37^{\circ} \mathrm{C}$ were summarized in Figures 5-8. As seen in the figures, higher swelling ratios were observed for PEG-DA hydrogels according to PEG-DA/HEMA based hydrogels. The swelling ratio of hydrogel decreased significantly with the incorporation of HEMA to PEG-DA. While the values of swelling percentage of PEG-DA hydrogels were ranged between 80 and $86 \%$, swelling percentage of PEG-DA/HEMA hydrogels were ranged between 43 and $49 \%$. The swelling of hydrogels usually depends on the $\mathrm{pH}$. As illustrated in these figures, at $\mathrm{pH} 6.8$ has the highest swelling ratio for all hydrogels. 


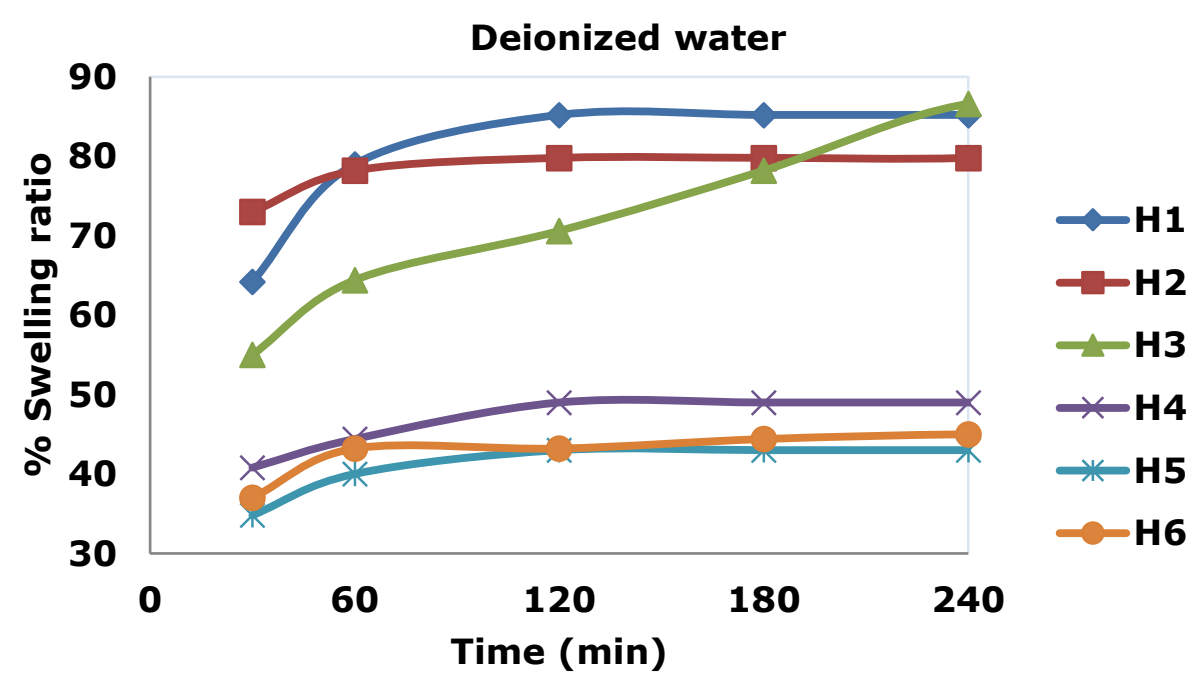

Figure 5: Swelling weight ratio of the studied hydrogels in deionized water.

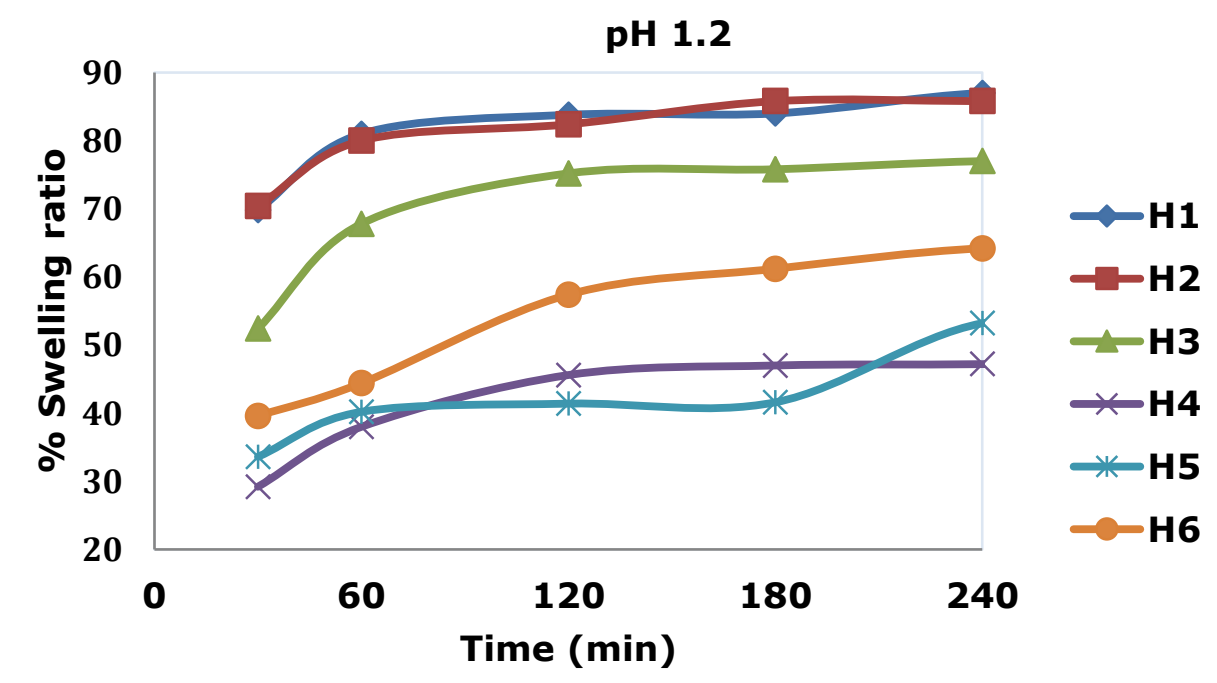

Figure 6: Swelling weight ratio of the studied hydrogels in $\mathrm{pH} 1.2$. 


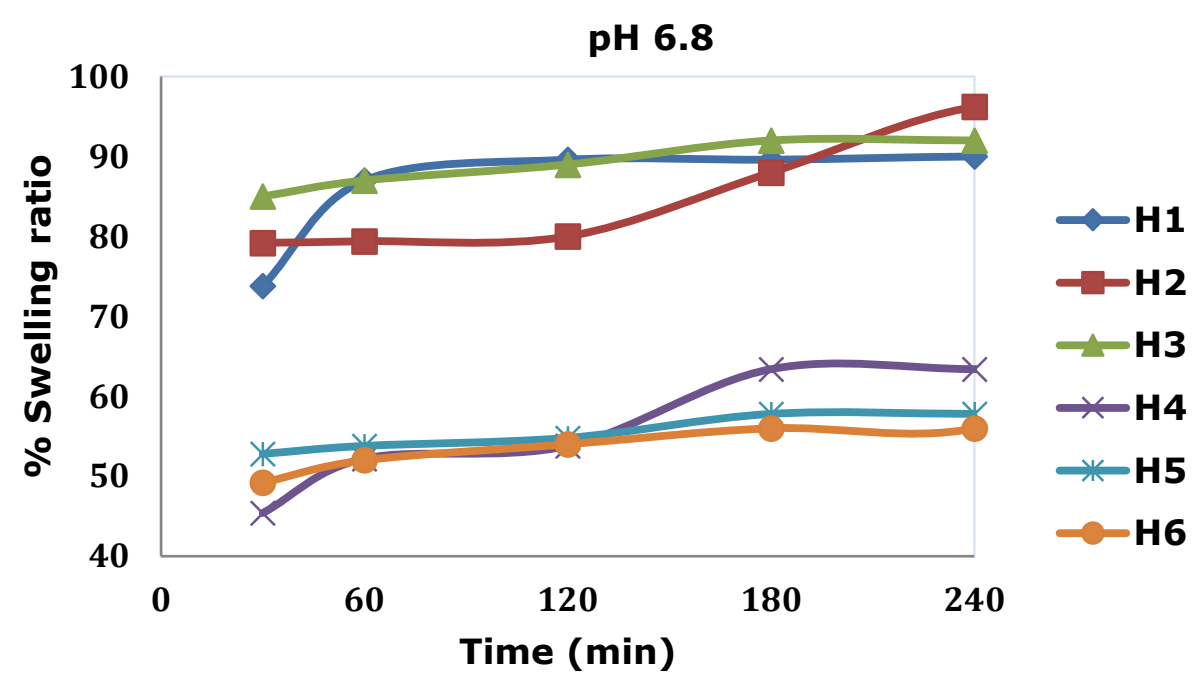

Figure 7: Swelling weight ratio of the studied hydrogels in $\mathrm{pH} 6.8$.

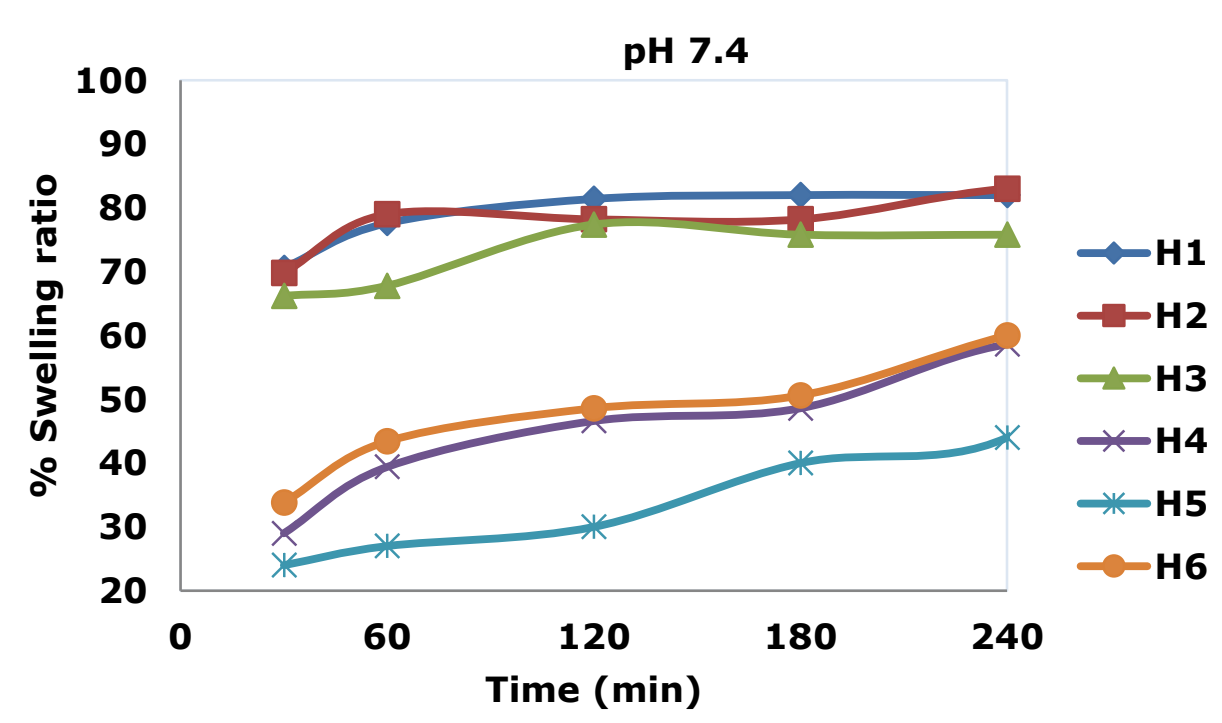

Figure 8: Swelling weight ratio of the studied hydrogels in $\mathrm{pH} 7.4$. 
Senol S, Akyol E. JOTCSA. 2019; 6(1): 1-14.

\section{Donepezil $\mathrm{HCl}$ release analyses}

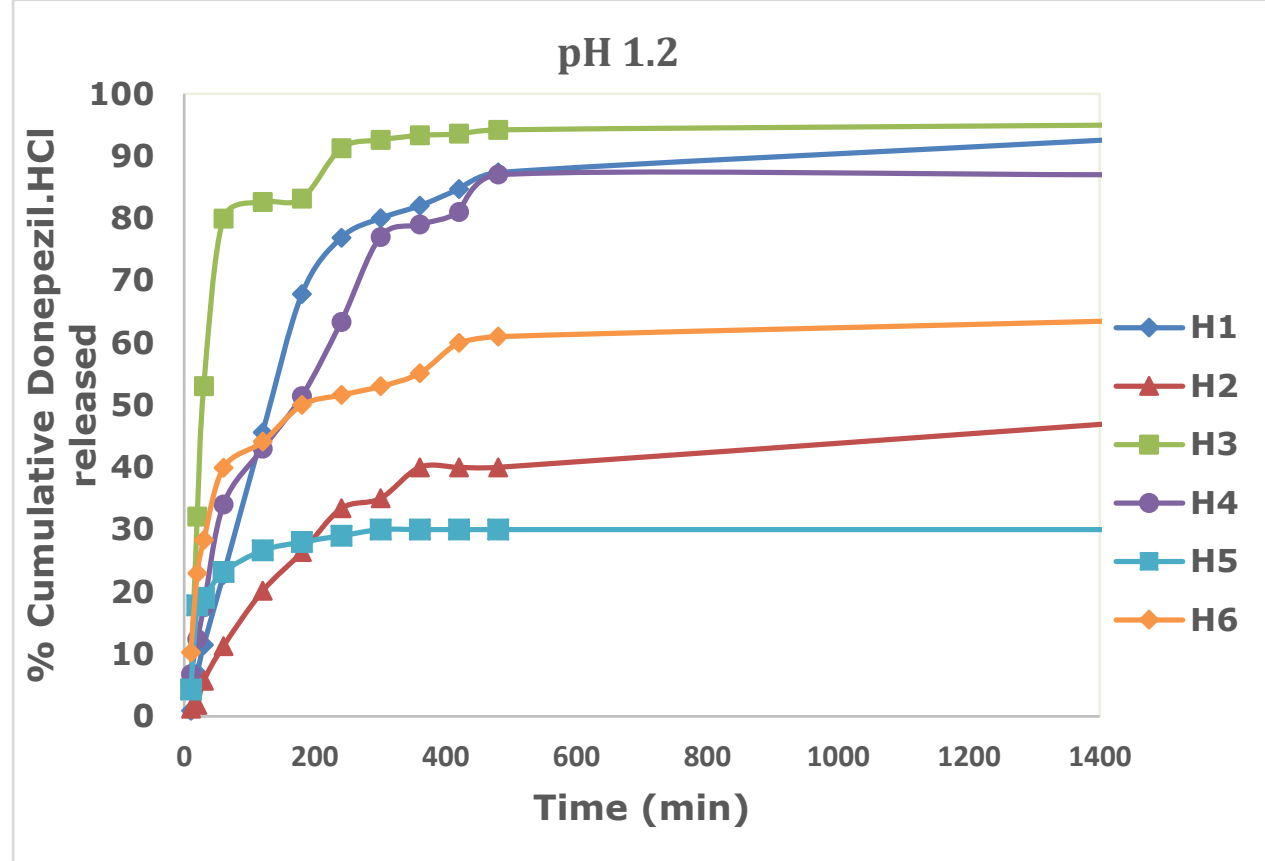

Figure 9: Release ratio of hydrogels in $\mathrm{pH} 1.2$. 


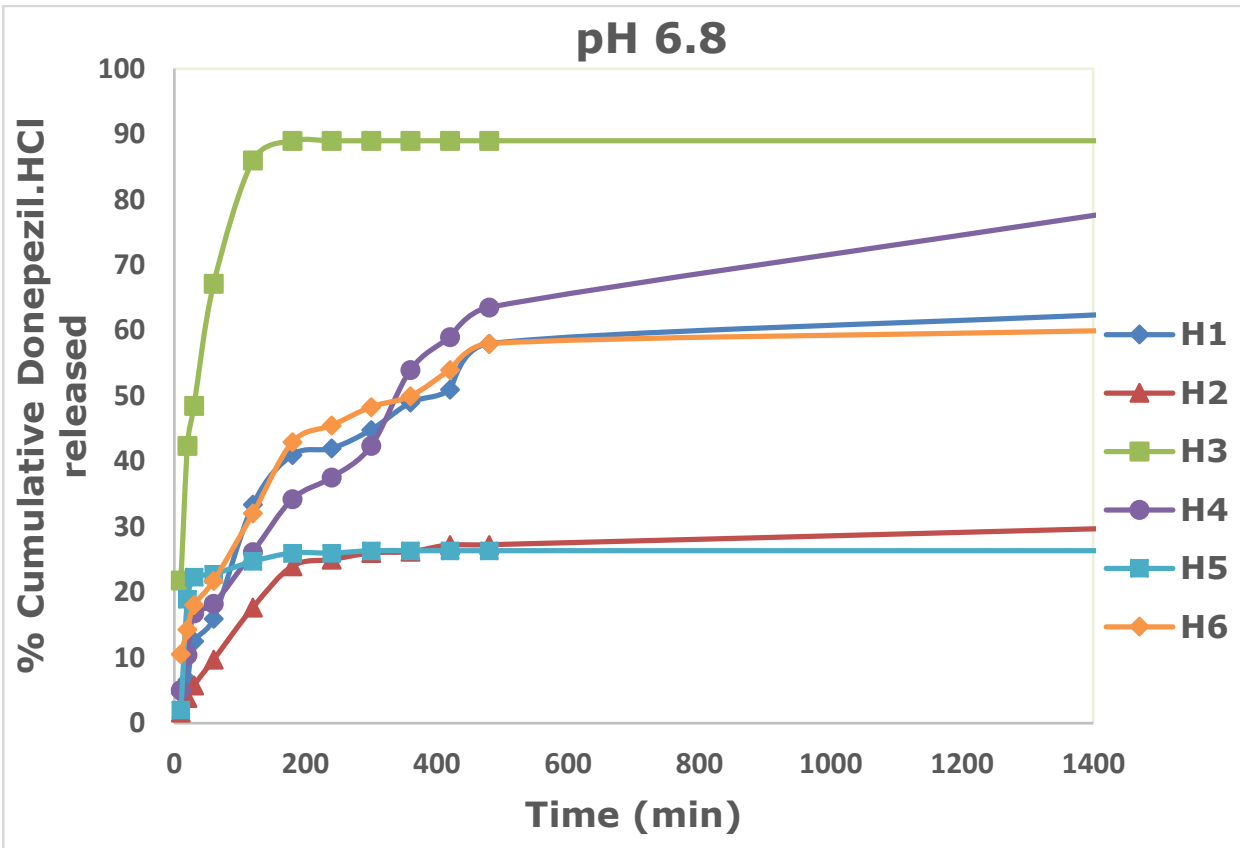

Figure 10: Release ratio of hydrogels in $\mathrm{pH} 6.8$.

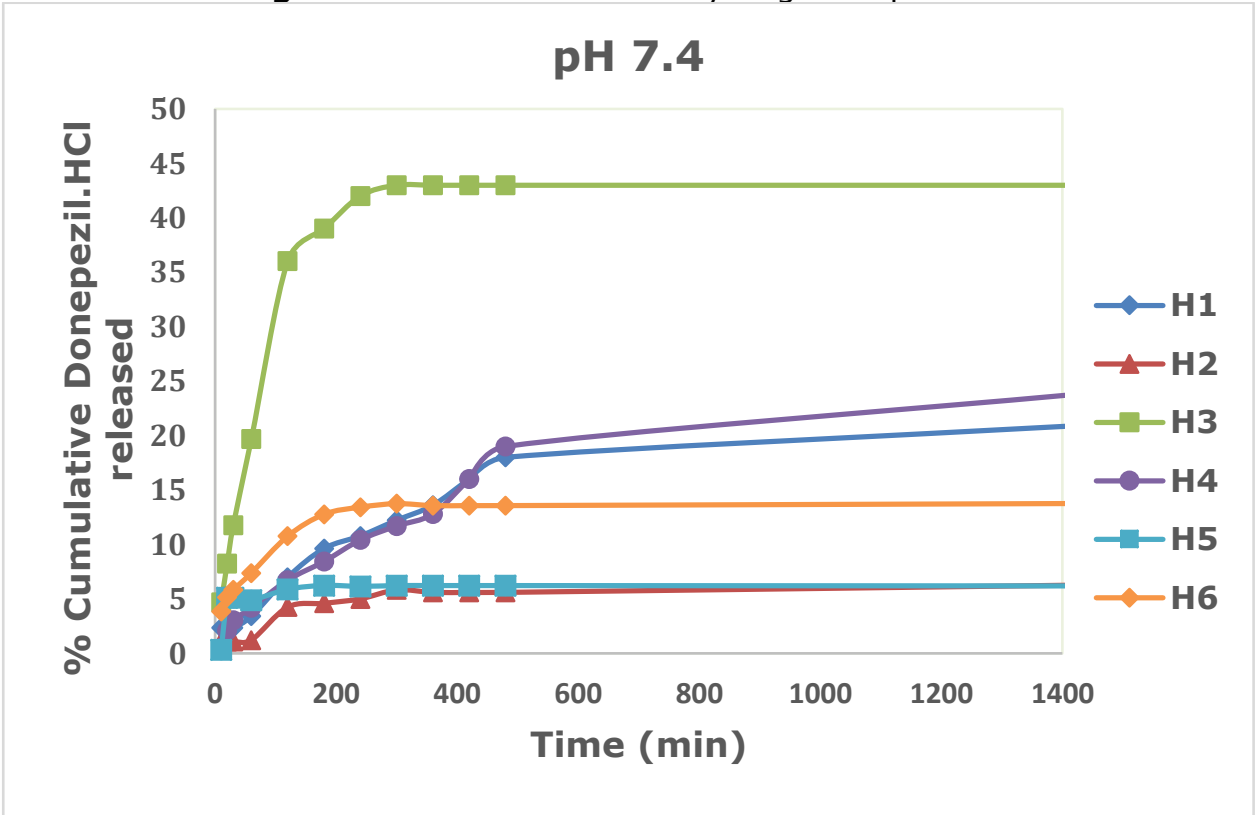

Figure 11: Release ratio of hydrogels in $\mathrm{pH} 7.4$.

Figures 9, 10 and 11 show the percent cumulative release of the pharmaceutical ingredient from synthesized hydrogels at simulated media, at $37^{\circ} \mathrm{C}$. It has been found that H3 hydrogel (hydroxyapatite modified
PEG-DA, in the presence of Irgacure 2959 as a photo-initiator shows the highest release. The results demonstrated that synthesized hydrogels using Irg 184 released the minimum amount of donepezil 
hydrochloride. Also, PEG-DA/HEMA hydrogels were very $\mathrm{pH}$ sensitive. The amount of drug released increased with increasing $\mathrm{pH}$. Similar results obtained from our previous studies $(4,29)$.

\section{CONCLUSION}

In the presented study, the synthesis of PEG-DA/HAp and PEG-DAHEMA/HAp hydrogels was achieved by UV photopolymerization. According to swelling and release analysis of hydrogels in different $\mathrm{pH}$ environments, the synthesized hydrogels exhibited a pH sensitive behavior. The release was slower when the $\mathrm{pH}$ was lower. Morever, both swelling and release behavior of hydrogels were highly influenced by the type and amount of photoinitiators. The results in the present investigation confirm the controlled release of Donepezil $\mathrm{HCl}$. These data suggested that, this kind of hydrogels may be useful for utilization in the release of drug.

\section{REFERENCES}

1. Hagel V, Haraszti $T$, Boehm $H$. Diffusion and Interaction in PEGDA Hydrogels. Biointerphases. 2013;8:36.

2. Rahimi $S$, Khoee $S$, Ghandi $M$. Development of Photo and pH Dual Crosslinked Coumarin-Containing Chitosan Nanoparticles for Controlled Drug Release, Carbohydrate Polymers. 2018;201:236-45.

3. Dash S, Murthy P.N, Nath L, Chowdhury P. Kinetic Modeling On Drug Release From Controlled Drug Delivery Systems. Polish Pharmaceutical 2010;67:217-23.

4. Senol S, Akyol E. Synthesis and Characterization of Hydrogels Based on poly(2-hydroxyethyl methacrylate) for Drug Delivery Under UV Irradiation. Journal of Materials Science. 2018; 53:14953-63.

5. Akyol E, Senol S, Dogan O. Controlled Release of Donepezil Hydrochloride From the Ternary Sodium Alginate Based Hydrogels. Bulgarian Chemical Communications. 2017;49:57-63.

6. Wang $Z$, Zhang $H$, Chu J.A, Jackson J, Lin K, lim C.J, Lange D, Chiao M. Mechanically Enhanced NestedNetwork Hydrogels as a Coating Material for Biomedical Devices. Acta Biomaterialia. 2018;70:98109.

7. Ponnuvelu D.V, Kim S, Lee J. Polyethyleneglycol Diacrylate Hydrogels

with Plasmonic Gold Nanospheres Incorporated via Functional Group Optimization. Micro and Nano Systems Letters. 2017;5:21.

8. Chiu Y-C, Brey E.M, Pérez-Luna M.B. $A$ Study of the Intrinsic Autofluorescence of Poly(ethylene glycol)-co-(L-Lactic acid) Diacrylate. Fluoresc. 2012;22:907-13.

9. Ayhan $\mathrm{H}$, Ayhan F. Photocrosslinked Poly(Ethylen Glycol) Hydrogels for Controlled Drug Delivery. Turk J Biochem. 2014; 39(4):403-15.

10.Ural-Kayalık H, Çetin S. Synthesis and Drug-release Properties of Biodegradable Hydrogels Having bcyclodextrin. JOTCSA. 2017;4(1):415-30.

11. Bat E. Hydroxyethyl Methacrylatebased Nanocomposite Hydrogels with

Tunable Pore Architecture. JOTCSA. 2016;3(3):607-22.

12. Garćıa-Uriostegui L, Delgado E, Melendez-Ortiz H.I., Camacho- 
Villegas T.A. , Esquivel-Solís $H$, Gatenholm p, Toriz G. Carbohydrate Polymers.2018; 201:490-9.

13. Islas L, Burillo G, Ortega A. Graft Copolymerization of 2Hydroxyethyl Methacrylate onto Chitosan Using Radiation Technique for Release of Diclofenac. Macromolecular Research. 2018;26:690-5.

14. Cao $X-Y$, Wen $F$, Bian $W$, Cao $Y$, Pang S-J, Zhang W-K. Preparation and comparison study of hydroxyapatite and Euhydroxyapatite. Front. Mater. Sci. 2009;3:255-8.

15. Sani T, Adem M, Fetter G, Bosch P, Diaz I. Defluoridation Performance Comparison of Nanohydrotalcite/Hydroxyapatite Composite with Calcined Hydrotalcite and Hydroxyapatite. Water Air Soil Pollut. 2016;227:90.

16. Verma D, Kattı S-K, Kattı D-R. Effect of Biopolymers on Structure of Hydroxyapatite and Interfacial Interactions in Biomimetically Synthesized Hydroxyapatite/Biopolymer Nanocomposites. Annals of Biomedical Engineering. 2008;36:1024-32.

17. Göktürk S. Effect of Hydrophobicity on Micellar Binding of Carminic Acid. Journal of Photochemistry and Photobiology A: Chemistry. 2005: 169:115-21.

18. Ayhan H, Ayhan F. Water based PHEMA Hydrogels for Controlled Drug Delivery. Turk J Biochem. 2017;43:3.

19. Kamoun E-A, Abu-Seaid M.A., Doma A.S., Menzel $H$, Chen X. Influence of Degree of Substitution and Folic Acid Coinitiator on pullulan-HEMA Hydrogel Properties
Crosslinked Under Visible Light Initiating system. Biomac. 2018;116:1175-85.

20. Liew K-B, Tan Y.T.F, Peh K-K. Characterization of Oral Disintegrating Film Containing Donepezil for Alzheimer Disease. AAPS PharmSciTech. 2012;13:13442.

21. Zheng $\mathrm{H}$, Niu $\mathrm{S}$, Zhao $\mathrm{H}$, Li S, Jiao J. Donepezil Improves the Cognitive Impairment in a Tree Shrew Model of Alzheimer's Disease Induced by Amyloid- $\beta 1-40$ via Activating the BDNF/TrkB Aignal Pathway. Metabolic Brain Disease.2018;1-14.

22. Wang $Y-R$, Yang $Y-H$, Lu $C-Y$, Lin S-H, Chen S-H. Trace Analysis of Acetylcholinesterase Inhibitors with Antipsychotic Drugs for Alzheimer's Disease by Capillary Electrophoresis with on Column Field-Amplified Sample Injection, Anal Bioanal

Chem.2013;405:3233-42.

23. Cutuli D, Bartolo P.B., Caporali P, Tartaglione A-M.,Oddi D, D'Amato F-R, Nobli A, D'Amelio M, Petrosini L. Neuroprotective Effects of Donepezil Against Cholinergic Depletion. Alzheimer's Research \& Therapy.2013;5:50.

24. Choi Y, Rhee S-J, Jang I-J, Yu K-S, Yim S-V, Kim B-H. Bioequivalence Study of Donepezil Hydrochloride in Healthy Korean Volunteers. Transl Clin Pharmacol. 2015;23(1):26-30.

25. Abonassif M.A, Hefnawy M.M, Kassem M.G, Mostafa G.A.E. Determination of Donepezil Hydrochloride In Human Plasma and Pharmaceutical Formulations by HPLC with Fluorescence Detection. Acta Pharm. 2011; 61:403-13. 
26. Barot T.G., Patel P.K. RP-HPLC Method for the Estimation of Donepezil

Hydrochloride Dosage Form. EJournal of Chemistry. 2009;6(2):594-600.

27. Chothe P.P, Subramanian R.C., Kadam V.J. Stability Assessment Of Donepezil Hydrochloride Using Validated RP-HPLC Method. Research Journal of
Pharmaceutical, Biological and Chemical Sciences. 2010;1(3):296.

28. Lakka NS, Goswami N. Solubility and Dissolution Profile Studies of Gliclazide in Pharmaceutical Formulations by HPLC. Int Res J Pharm. 2012; 3(6):126-9.

29. Senol S, Akyol E. Controlled Release of Donepezil Hydrochloride From PEG-DA Hydrogels. Bulgarian Chemical Communications. 2018; 50:12-17. 
